\title{
EL DISCURSO DE LOS LEGTORES ESPAÑOLES EN LAS CELEBRACIONES LITÚRGICAS: CARACTERÍSTICAS Y DEFICIENCIAS NO VERBALES
}

\author{
Fernando POYATOS \\ Universidad de New Brunswick (Canadá)
}

\section{RESUMEN}

Las deficiencias en la lectura de textos bíblicos en la Misa católica en España -no siempre debidas al nivel socioeducacional de los lectores, sino a su grado de sensibilidad personal hacia esos textos y a su falta de formación bíblica y litúrgica-justifica, como fenómeno sociolingüístico peculiar, un análisis de ese discurso oral leído. Estas deficiencias dependen concretamente: del uso incorrecto de una de las categorías del paralenguaje, las 'cualidades primarias'; de la interpretación de los signos puntuarios (no siempre correctos en los textos), esenciales en el discurso leído; de las funciones de los significativos, pero a menudo ignorados, silencios o pausas; en mucho menor grado, del gesto dentro de la triple estructura lenguaje verbal-paralenguaje-kinésica; y de la existencia de ciertos ejes interactivos definidos por dos posibles modos de mirada: hablada y silenciosa.

PALABRAS CLAVE: discurso oral leído, comunicación no verbal, interacción.

\section{AbSTRACT}

The frequent deficiencies in the reading of biblical texts in the Catholic Mass in Spain -not always due to the readers' socioeducational level but to the degree of their personal sensitiveness toward those texts and their lack of biblical and liturgical knowledge- justifies an analysis of that oral read discourse as a peculiar sociolinguistic phenomenon. These deficiencies depend specifically on: the incorrect use of one of the paralinguistic categories, 'primary qualities'; the interpretation of punctuation symbols (not always correct in the texts themselves), quite essential in read oral discourse; the functions of the significant, but often ignored, silences or pauses; in a much lesser degree, the gestures within the triple structure verbal language-paralanguage-kinesics; and the presence of some interactive axles defined by two possible kinds of regard: spoken and silent.

KEYWORDS: read oral discourse, nonverbal communication, interaction.

Fecha de recepción: 09/01/2019

Fecha de aceptación: 01/02/2019

Fecha de la versión definitiva: 03/02/2019 
1. EL DISCURSO ORAL DEL LECTOR LITÚRGICO: «LEER»Y «PROCLAMAR»

1.1 Así como se han tratado tan a menudo, en las páginas de Oralia y otras publicaciones lingüísticas, las características del discurso oral en diversas situaciones, grupos de población e incluso ocupaciones, no parece haberse estudiado un tipo de discurso tan diariamente presente en todos los sectores de la sociedad como es el de los lectores de los textos bíblicos en la Misa, concretamente la católica. Sin embargo, a diferencia de lo que ha sido para mí una experiencia positiva en Canadá y Estados Unidos buena parte de mi vida, en muchos lugares de España siempre he observado una frecuente mala calidad -desgraciadamente, no advertida por muchos de sus oyentes, como he comprobado- de lo que debe ser una lectura digna de esos textos, considerados en el mundo cristiano (y, para el Antiguo Testamento, en el judío) como palabra de Dios y, por tanto, sagrados.

De hecho, estas deficiencias constituyen un interesante fenómeno sociolingüístico que, aunque lo presenciamos más en hablantes de nivel medio y bajo (entre los cuales brillan las excepciones debido a una mayor sensibilidad personal hacia lo que leen), también se da en personas cultas. Evidentemente, la lectura en voz alta ante una asamblea religiosa requiere habilidades muy concretas, una actitud reverente hacia lo que se está leyendo y un contacto habitual con esos textos; de no ser así, el beneficio que debe aportar su lectura comunitaria disminuye notablemente si, por muy claro que uno lea, lo hace precipitadamente, o insípidamente, o cometiendo errores, o sin variación alguna en los rasgos de la voz según se trate de un diálogo, de un pasaje dramático, de trágica visión, gozoso, de exhortación, de lamentación, orante, etc.

El que todos, con mayor o menor frecuencia, seamos testigos de esta realidad justifica un breve análisis aplicando aspectos no verbales del discurso que yo mismo he tratado en las páginas de Oralia (Poyatos 1998, 2003, 2006, 2012, 2016a).

1.2 Dentro del campo de la liturgia -donde destacan numerosas manifestaciones de la comunicación no verbal interpersonal y con el entorno (Poyatos 2017)-, citemos, para empezar, dos fuentes de autoridad que al menos sugieren la deseada calidad de lectura tan frecuentemente no conseguida. La primera es la Ordenación General del Misal Romano (guía principal para toda la liturgia), al referirse al «lector instituido» y al llamado lector de facto (o sea, simplemente designado) «a falta de instituidos», añadiendo: «Si falta un lector instituido, desígnense otros [...] que sean verdaderamente idóneos para desempeñar este oficio y estén esmeradamente formados» (núm. 101). Otro documento importante, El Sacramento de la 
Redención, aconseja que el lector «haya recibido la formación litúrgica correspondiente...» (núm. 46). De hecho, sin embargo, la inmensa mayoría de los lectores, buenos o malos, no están realmente «formados» y están muy lejos de ser «idóneos» para hacer una lectura digna. Por eso he impartido cursillos en varias ocasiones, tanto a seglares como a sacerdotes y religiosos, y he preparado un detallado estudio-guía para este ministerio de tanta responsabilidad, pero a veces tan deficiente en su praxis (Poyatos 2016b).

1.3 En una ocasión vi en la televisión canadiense a un buen actor profesional que, en un programa de la Iglesia Pentecostal, leyó el Salmo 23, el más universalmente conocido y memorizado del Salterio, «El Señor es mi pastor». Poco más tarde lo leyó también el pastor y, al terminar, el actor se acercó a él y le dijo visiblemente conmovido: «I know the psalm, but you know the Shepherd!» («Yo conozco el salmo, ipero usted conoce al Pastor!»). Comprendemos lo que quiso decir el actor, pero, de haber concretado en qué basaba su apreciación, se habría referido -como yo había visto y oído- no a la parte verbal de su discurso, que él también sabía de memoria, sino a sus características no verbales, es decir, su paralenguaje, sobre todo, y su kinésica, esta siempre muy moderada en los lectores litúrgicos.

1.4 Como primer contacto con el tema que nos ocupa, recordemos, de uno de los libros del Antiguo Testamento llamados históricos, el libro de Nehemías, un pasaje bien conocido donde intuimos la calidad paralingüístico-kinésica de aquella histórica lectura del Libro de la Ley ${ }^{1}$ por parte del sacerdote Esdras al pueblo judío cuando, en el siglo vi a. C., habían vuelto del destierro en Babilonia para reconstruir el Templo de Jerusalén:

... el sacerdote Esdras trajo el libro de la ley ante la comunidad, hombres, mujeres y cuantos tenían uso de razón [...]. Leyó el libro [...] desde la mañana hasta el mediodía [...]. Todo el pueblo escuchaba con atención la lectura [...]. Esdras abrió el libro [...] al abrirlo, el pueblo entero se puso de pie [...]. Leyeron el libro de la ley de Dios con claridad y explicando su sentido, de modo que entendieran su lectura $[\ldots]$ todo el pueblo lloraba al escuchar las palabras de la ley. $(8: 2,3,5,7-8,9)^{2}$

Evidentemente, uno puede leer cualquier texto bíblico con mucha soltura, incluso con naturalidad, pero estar su lectura bien lejos de ser una

\footnotetext{
1 Es decir, el Pentateuco (o Torá judía, los primeros cinco libros del Antiguo Testamento).

${ }^{2}$ Las citas, por la Sagrada Biblia, Conferencia Episcopal Española (2011).
} 
proclamación, si simplemente lee, sin suscitar en sus oyentes el deseo de escuchar. Esto refleja, en primer lugar, carencia de la recomendada preparación y el no haber sido imbuidos los lectores del hecho de que la proclamación de la Palabra de Dios es, después del ministerio del sacerdote, el más importante. Pero también indica falta de criterio en quienes deberían proporcionarles esa formación y no permitir a cualquiera leer en la iglesia -independientemente de su buena disposición u otras razones- sin estar seguro de que sabe hacerlo y de que lo ha leído antes en casa o, al menos, al asignársele; pues al ir enterándose el lector (si es que se entera) de lo que dice a medida que lo lee, delata ya desconocimiento de su cometido.

\section{Paralenguaje: Cómo decimos lo Que decimos}

Aunque, refiriéndose solo a los sacerdotes, la mencionada Ordenación General advierte: «La naturaleza de las intervenciones "presidenciales" exige que se pronuncien claramente y en voz alta» (núm. 32). Lo mismo podría decir de los lectores, en este caso aludiendo a la adecuada intensidad de la voz y a una precisa articulación en su discurso. Definamos el paralenguaje como:

Las cualidades y modificaciones no verbales de la voz y los sonidos y silencios independientes con que, simultáneamente o alternando dentro de la triple estructura del discurso, apoyamos o contradecimos sus coestructuras verbales (las palabras) y kinésicas (movimientos y posiciones corporales).

Sabemos que el paralenguaje abarca una amplísima gama de fenómenos comunicativos (Poyatos 1993) determinados, en primer lugar, por la anatomía y fisiología de los órganos fonatorios de cada persona (desde las fosas nasales, la boca y la laringe, hasta los músculos abdominales), rasgos inalterables que contribuyen a su imagen como lector o lectora y pueden influir en cómo se le perciba y en cómo desarrolle sus funciones. Pero tengamos en cuenta también el uso idiosincrásico o actitudinal, o ambos, que como hablantes hacemos de esos rasgos fónicos, produciéndolos incluso involuntaria e inconscientemente, pero siempre exteriorizando nuestras más íntimas actitudes más allá de las palabras. Por tanto, en la celebración litúrgica es importantísimo el paralenguaje, no solo el de los lectores sino el del mismo sacerdote cuando se dirige a su asamblea.

Siguiendo el esquema adjunto, «Resumen de los fenómenos paralingüísticos», identifiquemos al menos las cuatro categorías que he tratado con detalle en otros estudios (ej., Poyatos 1993, 1994, 2002a, 2002b, 2002c), pero concentrándonos solo en lo que debe aplicarse a quienes actúan de lectores en las celebraciones. 


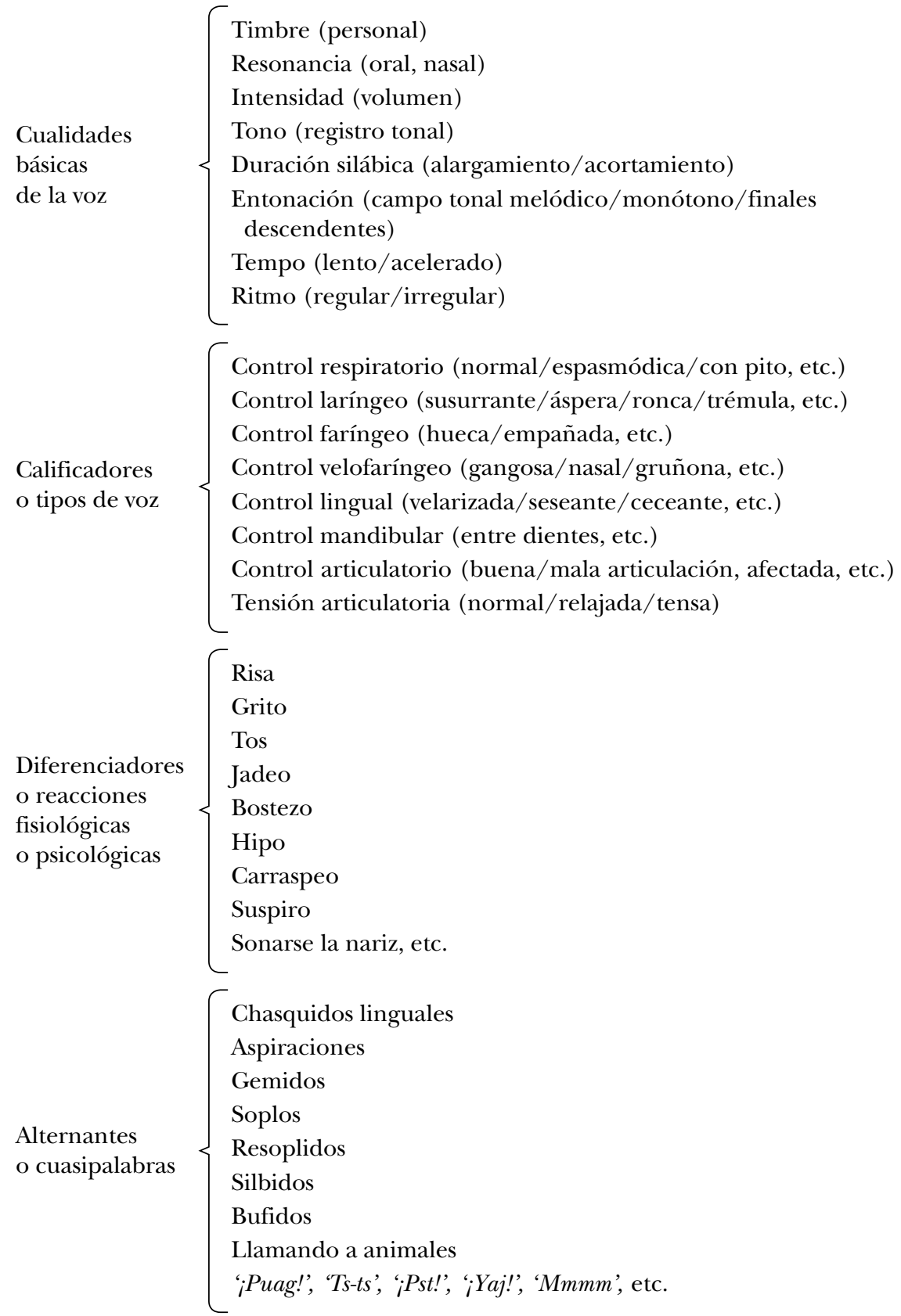




\section{CUALIDADES PRIMARIAS}

Los fenómenos paralingüísticos que he llamado cualidades primarias son las características fónicas fundamentales de cada persona -aunque usadas también intencionadamente-, condicionadas por factores biológicos (ej., el sexo y la edad para el timbre), fisiológicos (ej., anomalías en los registros causadas por crecimiento anormal de las bandas vocales o por terapia de hormonas), psicológicos (ej., por la personalidad, como la intensidad mayor del extrovertido), socioculturales, pero con variaciones geográficas (ej., el alargamiento silábico de los sureños estadounidenses) y ocupacionales (ej., el registro más alto de muchas enfermeras al hablar a los pacientes, pero no a sus compañeras). Para ver hasta qué punto son esenciales en la lectura litúrgica, comentémoslas brevemente aplicándolo a algunos de los muchos textos que se leen en la iglesia. Excluyamos el timbre de voz por tratarse del registro o altura musical propio de cada hablante (que diferenciamos incluso sin saber lo que está diciendo: «AAhí está Antonio!»), según la longitud y grosor de las bandas vocales (bajo en los hombres, por ser más largas y gruesas y vibrar más despacio, y más alto en mujeres y niños); lo que no quita para que el posible efecto negativo de una voz sea superado, como en cualquier otra situación social, gracias no solo a unos rasgos faciales dinámicos del lector, percibidos positivamente dentro de la estructura lingüístico-paralingüístico-kinésica del discurso, sino a su personalidad.

\subsection{Resonancia}

Como rasgo individualizador fijo (no producida intencionalmente), según dónde resuenen más las vibraciones de las bandas vocales -debido al tamaño y forma de las cavidades faríngea, oral y nasal-, emitimos nuestra voz con uno de estos tipos de resonancia: oral, es decir, principalmente en la boca, la más clara y rotunda (latín rotundus, 'boca redonda'), percibida (incluso sin ver al hablante) como propia de características personales positivas, por tanto idónea para un lector y aún más para presidir la celebración; faríngea, percibida más positivamente en el hombre (ej., como de madurez) que en la mujer (ej., como hombruna); nasal, si parte del aire tiende a salir por la nariz, lo cual puede llegar a resultar desagradable para los oyentes y ser motivo de distracción al hacerles pensar cómo suena esa voz.

\subsection{Intensidad o volumen}

3.2.1 Sabemos que este rasgo depende del esfuerzo respiratorio y articulatorio, que utilizamos gramaticalmente (ej., menor haciendo un inciso: 
«Mañana, si hace bueno, vamos de excursión») y, sobre todo, actitudinalmente. Aparte de los aspectos propios de un estudio más detallado (culturales, situacionales, funcionales, patológicos, etc.) (Poyatos 1993: 179-182), digamos que la voz ideal para las lecturas litúrgicas es la que, sin gritar, se proyecta fácilmente en cualquier circunstancia; pero a veces hay una molesta falta de uniformidad en la intensidad de la voz de los distintos lectores en una misma celebración, por no procurar que se asemejen en esta y las demás cualidades.

3.2.2 Por otra parte, aunque una intensidad media-alta se gana mejor la atención de un auditorio, es evidente que también depende de la que requiera cada texto. Por ejemplo, la voz vehemente y la voz suave se adoptarían alternativamente al leer este diálogo, en Juan 13: 6-9, entre Jesús (media) y Pedro (vehemente), en el cual las últimas palabras de Jesús podrían leerse también con vehemencia.

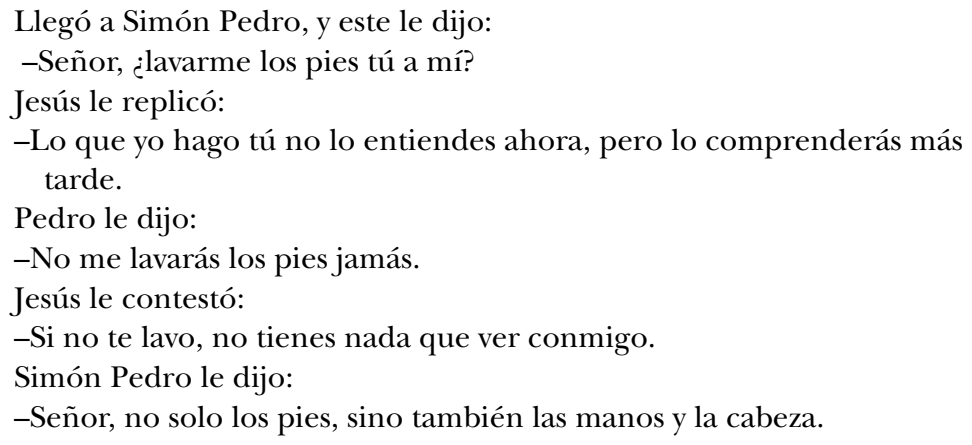

3.2.3 A propósito de la intensidad de la voz, las respuestas «Amén»y «Y con tu espirítu» a lo largo de la Misa, son también piedras de toque para observar en cualquier celebración la tan frecuente frialdad del discurso litúrgico por parte de los fieles. Se supone que un 'Amén' (hebreo ‘¡Así sea!', ‘Así es!') debe sonar como un gran, «¡Sí!» tras lo que se haya dicho o leído, no gritado, pero sí vehemente, bien articulado y con adecuada (aunque leve) expresión facial, y no con un registro apagado y una equivalente falta total de expresión facial. De hecho, el «Amén» que responde a la alabanza "iPor Cristo, con él y en él, a ti, Dios Padre omnipotente, en la unidad del Espíritu Santo, todo honor y toda gloria por los siglos de los siglos!», se ha llamado históricamente «el gran Amén», pero vemos que está muy lejos de sonar como cuando en el siglo IV cuenta san Jerónimo que hacía temblar en Roma los templos paganos. 


\subsection{El tono o registro y el campo tonal}

El tono -el rasgo más polivalente de la voz y con más sutiles variaciones simbólicas- es causado por las vibraciones más rápidas (agudo) o más lentas (grave) de las bandas vocales, de modo que el nivel tonal o registro que domina una porción de nuestro discurso es lo más significativo y elocuente y, si es medio-alto, realza mejor una idea; así que el campo tonal es el comprendido entre el registro más bajo y el más alto, o sea, de amplio a reducido y con una kinésica animada o monótona. Por ejemplo, usamos una curva de entonación ascendente para preguntar: «Por favor, ¿podría decirme por dónde se va a...?»; ascendente, sostenida y con mayor intensidad de voz, para advertir: «¡Cuidado, que se cae!»; pero un tono más grave, y entonación descendente, para expresar conmiseración: «Pobre, se conoce que no tenía para comer».

El DRAE define proclamar como «Publicar en alta voz una cosa para que se haga notoria a todos», es decir, con una vehemencia variable y nunca apagadamente. Por eso la verdadera proclamación de la Palabra requiere un tono proclamativo; sin embargo, suele leerse con un registro continuadamente bajo, intensidad demasiado apagada y terminando todas las frases con entonación descendente aunque no corresponda.

Dicho esto, sugeriré los símbolos que he utilizado en mis cursos para lectores -basados en mi estudio de esa parte importante de la liturgia (Poyatos 2016b)-, aunque nunca puedan representar fielmente esos diversos matices que precisamente realzan una buena lectura: el tono descendente con el signo $[\downarrow]$; el sostenido con $[\rightarrow]$ (evitando el mal hábito de dejar caer el tono de la voz al final de muchas frases y dar una molesta monotonía a la lectura); el sostenido bajando ligeramente al final con $\left[\rightarrow \_\right]$; el sostenido con un ligero ascenso final $\left[\rightarrow^{-}\right]$; y el ascendente con $[\uparrow]$; y, dada la típica tendencia de muchísimos lectores a bajar el tono en cada final de frase aunque corresponda el sostenido, indiquemos ambas alternativas con $[\rightarrow / \downarrow]$ (aunque prefiriendo la primera) para juzgar su efecto.

Apliquemos estos tonos finales de la curva entonativa a un fragmento de Filipenses 2: 6-7, usando el signo [ $\mathrm{J}$ ] para indicar la continuidad entre dos líneas (lo que en poesía llamamos encabalgamiento).

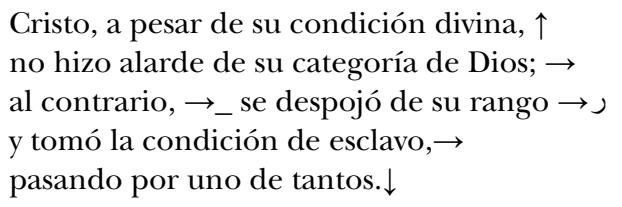

La diferencia entre leer estas palabras con un registro medio o con uno más alto y más enérgico (de mayor volumen o intensidad) será precisamente 
la diferencia entre hacerlo sonar como algo leído una vez más, 'porque toca', o hacer que la asamblea perciba a un lector como convencido de lo que está leyendo.

Aún resulta más descorazonador oír leer -como ocurre casi siempreun salmo gozoso, concretamente de alabanza, con registros sostenidos, intensidad media y finales de frase con tono descendente. Fácilmente podemos imaginar las siguientes estrofas de los salmos 149 y 96 en su lectura habitual, y en la que deberíamos oír, es decir, como se oyen, cantados o recitados, en diversas Iglesias no católicas y en las sinagogas judías:

SALMO 149:

Alabad al Señor en el cielo, alabad al Señor en lo alto; alabadlo, todos sus ángeles, alabadlo, todos sus ejércitos.

SALMo 96:

Cantad al Señor un cántico nuevo, cantad al Señor, toda la tierra; cantad al Señor, bendecid su nombre.

Proclamad día tras día su victoria. Contad a los pueblos su gloria, sus maravillas a todas las naciones.

Alégrese el cielo, goce la tierra, retumbe el mar y cuanto lo llena; vitoreen los campos y cuanto hay en ellos, aclamen los árboles del bosque.

\subsection{Entonación}

La entonación de un lector o una lectora debe caracterizarse por el equilibrio y buen uso de los tonos altos y bajos y de los intervalos breves o amplios entre esos tonos (o sea, no interrupciones sino como transición de unos a otros). Por eso la entonación nos parece adecuada cuando es moderadamente melodiosa, es decir, sin altibajos exagerados, sino simplemente como nos gusta oír hablar a una persona; e inadecuada si es monótona, apagada o de soniquete, lo cual ocurre cuando el margen o campo entonativo tiene muy pocas variaciones.

En el discurso leído se dan muy frecuentemente defectos típicos de entonación que observamos también en las interrogaciones o preguntas, en las exclamaciones y en las interpolaciones cuando se intercala una idea como en un paréntesis, aunque no se escriba con paréntesis [( )], sino 
entre rayas [- - ], [- - ] o comas [, ,]. Muy generalizada es entre los lectores la tendencia a usar una entonación descendente en todos los finales de frase, aun en los casos en que no lo requiere en absoluto, contribuyendo así a un discurso que se hace más irreal todavía cuando se trata, por ejemplo, del de un profeta exhortando al pueblo o anunciándole, seis siglos antes, la llegada del Mesías, lo cual leen con una insípida monotonía que no sugiere el más mínimo entusiasmo. Imaginemos, en cambio, al profeta Isaías proclamando vehementemente, no como lo oímos en la iglesia, el mensaje de Dios en este pasaje (40:1-8), con los siguientes rasgos paralingüísticos:

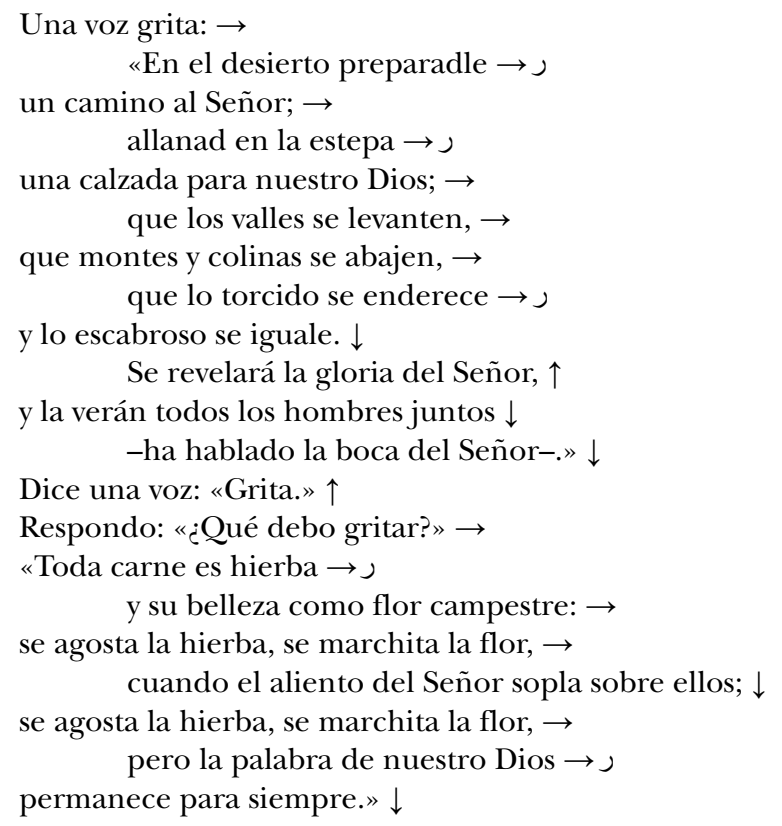

Consideremos también la entonación en el conocido Salmo 51 (3-4), en el que el rey David expresa desgarradoramente su arrepentimiento y petición de perdón divino tras su triple pecado de adulterio, engaño y asesinato. En estos versículos, correctamente leídos con la vehemencia y el tono (registro) propios de una angustiosa imploración -aunque sin llegar el lector litúrgico a un dramatismo teatral-, debe aplicarse a los finales de línea una entonación más bien sostenida, es decir, ni descendiendo ni elevándose (sólo muy ligeramente descendente antes de cada [;]), para que vayan encadenándose las distintas súplicas como eslabones, sin interrupción y con el mismo carácter emocional:

Misericordia, Dios mío, por tu bondad, $\rightarrow$ por tu inmensa compasión borra mi culpa; $\rightarrow$ 


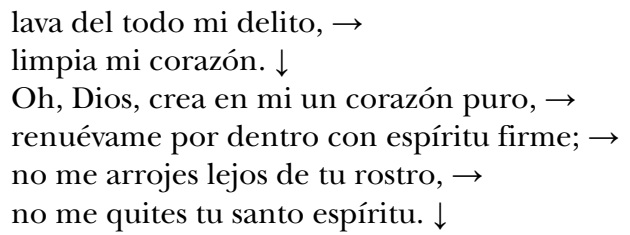

Sin embargo, la lectura que solemos oír hace descendentes todos los finales indicados aquí como sostenidos, suprimiendo totalmente el debido carácter implorativo.

En cuanto a la entonación al ver los signos de interrogación [ ¿ ?], muchos lectores y lectoras $-\mathrm{y}$, sin excepción, los más jovencitos- leen esas frases como suelen hacer los niños, es decir, bajando el tono al aproximarse al final de la frase interrogativa y elevándolo marcadamente justo al final de la pregunta, cuando ellos mismos nunca lo harían así preguntándole algo a alguien, lo cual suena infantil y simplemente irreal, característica de los malos lectores, aunque lean lo demás más o menos adecuadamente.

Por supuesto, las cualidades primarias en los intercambios verbales entre el sacerdote y los fieles durante la celebración reflejan su actitud mutua, como sugiere la Ordenación General, «Ya que no son solamente señales externas de una celebración común, sino que fomentan y realizan la comunión entre el sacerdote y su asamblea» (34). Pero quien pretenda estudiar este tema in situ ha de tener en cuenta que esa asamblea suele ser muy variopinta y que, para empezar, quienes la forman carecen -más en unas ocasiones que en otras- de una común actitud hacia las celebraciones.

\subsection{Tempo}

Este rasgo del discurso consiste en la velocidad relativa de su emisión sucesiva de palabras y frases (incluyendo las pausas que alternan con ellas), que no debe ser ni muy lenta ni muy rápida, pues, por ejemplo, las palabras o frases significativas sonarán mejor si se enuncian reposadamente y con un lento énfasis, mientras que disminuiremos su importancia diciéndolas más rápidamente. Sin embargo, esto es bastante frecuente y hace que el lector no nos dé tiempo para pensar en ellas y dejar que se graben mejor en nuestra mente. Buen ejemplo lo encontramos en las palabras de Isaías profetizando siglos antes el sacrificio de Jesús, que el apóstol Felipe lee con el etíope, en Hechos 8: 32-33, donde a la pregunta puede dársele un tono medio con énfasis en «quién»:

Como cordero llevado al matadero, $\rightarrow$ como oveja ante el esquilador, $\uparrow$ enmudecía y no abrió la boca. $\downarrow$ 
Sin defensa, sin justicia se lo llevaron, $\downarrow$ ¿quién meditó su destino? $\rightarrow$

Lo arrancaron de la tierra de los vivos. $\downarrow$

Algo muy importante en todo texto leído en público es que si se lo leemos reposadamente captaremos nosotros mismos, en nuestro acto de lectura (Poyatos 2008: caps. 1-3), las palabras que van saliendo de nuestra propia boca y, a la vez que las decimos, podremos ir asimilándolas y saboreándolas mentalmente.

\subsection{El ritmo}

El tono de la voz, su entonación y su tempo o velocidad, que producen variaciones en el flujo verbal-no verbal del discurso (en este caso leído), deben hacer que el estilo de los lectores se distinga por su ritmo suavemente uniforme, sin pausas excesivas entre las palabras por creer, indiscriminadamente, que hay que leer despacio, como hacen algunos que han interpretado erróneamente el consejo: («iDespacio!»).

Sin embargo, no es infrecuente el extremo opuesto (lo cual confirma la natural cohesión interna de la triple estructura del discurso lenguaje verbalparalenguaje-kinésica), es decir: una lectura irregular, entrecortada y tan precipitada como la misma conducta kinésica yendo hacia el ambón y abandonándolo, es decir, rápidamente y sin hacer, antes y después, la obligada profunda inclinación (desde la cintura) al altar (o al obispo, si preside); no, como un tic nervioso de cabeza, hacia el sacerdote, o nada. Y será más adecuado el ritmo de un lector que esté relajado en el ambón y, mejor aún, que conozca ya el pasaje que está leyendo o al menos se haya preocupado de leerlo.

\section{Calificadores}

Además de esos rasgos básicos del discurso oral, producimos muchos tipos de voz, o calificadores, por medio de ciertos controles ejercidos en las zonas articulatorias, por ejemplo: control respiratorio (respiración normal, espasmódica, con pito asmático, etc.); control laríngeo (ej., voz susurrante, murmurada, halitante, áspera, ronca, dura, cascada, seca, estridente, trémula, de falsete, etc.); control faringeo (ej., con sequedad faríngea, o hueca, empañada, etc.); control velofaríngeo (porque entran en juego el velo del paladar y las fosas nasales, como en la voz nasal, gangosa, gruñona, etc.); control lingual (ej., voz palatalizada [la lengua contra el paladar, muy de niños], velarizada [la lengua demasiado alta], seseante, ceceante, etc.); control man- 
dibular (ej., hablando entre dientes, muy negativo ante una asamblea litúrgica); control articulatorio, desde una clara y correcta articulación hasta formas inadecuadas para un sacerdote que presida (ej., demasiado cuidada y afectada); tensión articulatoria (ej., voz relajada o tensa con un nivel medio óptimo).

Aparte de que hay tipos de voz característicos del repertorio paralingüístico de cada hablante, también posee este unos rasgos faciales permanentes percibidos positiva o negativamente, pero que se modifican al dinamizarse en la interacción, como se comenta más abajo. En el caso de quien habla ante a un auditorio, los tipos de voz que más deben evitarse son: la voz hueca, por alargamiento de la faringe, con tonos muy bajos y una resonancia cavernosa o sepulcral; la voz cascada, laringalizada, típica de algunos lectores ancianos, por la compresión natural de su laringe; la voz dura, es decir, desabrida, agria, etc., por excesiva tensión de las bandas vocales; la voz ronca permanente, de fisiología no bien definida, como si pasara por un filtro de aspereza que le quita claridad, tan negativa como la voz gutural [cuando es demasiado «de garganta»]; la voz estridente, como chirriante, y la voz chillona, ambas agudas y penetrantes, por la constricción de las bandas vocales y el mayor esfuerzo muscular, tampoco aptas para este ministerio; la voz empañada, porque se adelanta la lengua separándola de la faringe y se relajan los arcos faucales (donde está la úvula), haciendo que suene como si habláramos detrás de una bufanda; la voz excesivamente ceceante o seseante, como en ciertas variantes del habla andaluza (Poyatos 2006) ${ }^{3}$; la voz entre dientes, murmurante o mascullante, difícil de entender porque no puede articularse bien si las mandíbulas no se separan normalmente al hablar, cosa que puede corregirse; la voz mal articulada (término un tanto vago), es decir, confusa, arrastrada, suprimiendo o alterando ciertos fonemas y, por tanto, distorsionando las palabras, de la cual suele decirse que la persona «pronuncia mal» o que «no vocaliza», problema que requiere: o abstenerse de leer en público o, sencillamente, esforzarse en pronunciar cada letra que en el texto representa un sonido.

\section{DifERENCIADORES Y ALTERNANTES}

Como sugiere el esquema adjunto, estas dos categorías paralingüísticas, que he estudiado detalladamente en los trabajos ya aludidos, a pesar de su importancia morfológica y funcional en tantas situaciones interactivas o no interactivas, quedan más bien fuera del campo concreto de la liturgia.

\footnotetext{
${ }^{3}$ Es decir, el cambio de la apico-alveolar $s$ en apico-interdental fricativa $c$ (ceceo, incluso mostrando la lengua en una predorsal-interdental y hasta dorso-interdental, inaceptables en un lector), y el de la ápico-interdental $c, z$ en predorsal fricativa $s$ (seseo).
} 
Los diferenciadores son reacciones fisiológicas que difícilmente se dan en el discurso del sacerdote en una celebración y, menos aún, en el de los lectores, con excepción de la tos y el carraspeo ocasionales -bien patológicos o por ansiedad consciente o inconsciente-, que interrumpen momentáneamente el discurso, pero sin afectar su recepción por parte de los oyentes si se lee adecuadamente.

En cuanto a la enorme variedad de los alternantes o cuasipalabras, algunos pueden darse con mayor o menor frecuencia en una homilía, según la personalidad y el estilo oratorio del predicador, pero no caben en la lectura de un texto bíblico.

\section{IGNORAR LA PUNTUACIÓN DEL TEXTO RESTA FUERZA AL DISCURSO Y SU MENSAJE}

Pocas veces apreciamos en el discurso de los lectores la debida pulcritud respecto a los signos puntuarios que van encontrando en el texto -no siempre correctamente puntuado, lo que supondría otro aspecto en un estudio más a fondo-, los cuales sugieren los cambios, ya mencionados, de intensidad o volumen, registros, tempo, alargamiento silábico y, en general, entonación ${ }^{4}$.

Podemos imaginar lo que sería leer los distintos libros de la Biblia cuando ni los párrafos ni las palabras estaban separadas en el texto, y las frases solo algunas veces, y cuando tampoco, hasta el siglo III, existían la coma, los dos puntos y el punto y coma; y hasta el siglo $\mathrm{V}$-con la Vulgata latina (traducción del griego por san Jerónimo) - no se separaron las palabras, y solo unos dos siglos más tarde se dejó de escribir todo con mayúsculas.

\section{Coma [,]}

Pocos lectores observan las funciones de las comas, las cuales, además de actuar a veces como paréntesis [, ,] sirven para separar pensamientos e imágenes distintos, y por eso hay que hacer esas brevísimas pausas y proclamar, no solo leer mal, cada una de esas porciones de texto separadamente

${ }^{4}$ Los símbolos puntuarios -que he estudiado como signos de las cualidades del discurso (Poyatos 1994c: cap. 5)- los fueron inventando arbitrariamente a través de los siglos, precisamente para hacer más vivas las lecturas piadosas durante las comidas en los refectorios de los antiguos monasterios y conventos medievales, donde se preservaban y copiaban los textos sagrados, hasta que, a partir del siglo XvIII, ni a impresores ni a escritores se les ocurrió inventar más, lo cual quiere decir que nuestro sistema adolece de limitaciones para realmente expresar ciertos textos tal como se escribieron. 
para así darle más realce, mientras que la pausa indicada por los dos puntos nos anuncian y preparan para una declaración importante. Por ejemplo, encontramos en Isaías 41:13:

$$
\begin{aligned}
& \text { Yo, } \rightarrow \text { el Señor, } \rightarrow \text { tu Dios, } \rightarrow^{-} \text {te agarro de la diestra } \rightarrow \jmath \\
& \text { y te digo: } \rightarrow \text { «o temas, } \rightarrow \text { yo mismo te auxilio.» } \downarrow
\end{aligned}
$$

Obviamente, no deben exagerarse esas pausas internas señaladas por las comas, pero tampoco hacerlas casi desaparecer leyendo de corrido, sino realzando «el Señor»y «tu Dios». También pueden servir las comas, por ejemplo, para enumerar los atributos de Jesucristo, que no deben simplemente leerse como haríamos con cualquier otra lista, sino, insistamos una vez más, con tono verdaderamente proclamativo, enunciando los tres primeros con un final de tono sostenido y ligeramente elevado (indicado aquí con $\left.\left[^{-}\right]\right)$, sostenido en el cuarto y sin descender hasta el último:

Y tal convenía que fuese nuestro Pontífice: $\rightarrow$ santo, $\rightarrow^{-}$inocente, $\rightarrow^{-} \sin$ mancha, $\rightarrow^{-}$separado de los pecadores $\rightarrow$ y encumbrado sobre el cielo. $\downarrow$ (Hebreos 7:26).

Dos puntos [:]

Volviendo a los dos últimos ejemplos, vemos generalmente que los lectores fallan al no hacer en los dos puntos [:] una pausa también breve, pero mayor que para las comas, cuya función es crear suficiente expectación por lo que sigue. En el primero, después de «y te digo [...] :», para que el oyente espere lo que sigue y lo escuche mejor: «yo mismo te auxilio». En el segundo, al leer «Pontífice:», es decir, antes de enumerar sus cualidades, sin apresurarse en los dos puntos. Pero los lectores suelen suprimir ambos momentáneos silencios, empobreciendo nuestra recepción de los textos bíblicos y, por tanto, disminuyendo su beneficio para sus oyentes.

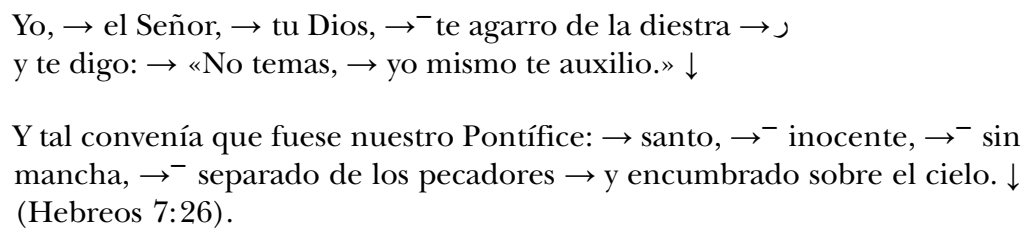

Punto y coma [;]

$\mathrm{Al}$ punto y coma [;] corresponde una pausa ligeramente mayor que la indicada por una coma -es decir, similar a la del punto y seguido-, la cual es 
necesaria para asimilar al máximo el significado de cada segmento. Sin embargo, es prácticamente suprimida por muchos lectores, en pasajes como este del Libro de los Hechos de los Apóstoles, 3:14-16, 17-18:

Rechazasteis al santo, $\rightarrow$ al justo, $\rightarrow$ y pedisteis el indulto de un asesino $\rightarrow$; matasteis al autor de la vida $\rightarrow$; pero Dios lo resucitó de entre los muertos, $\rightarrow^{-}$y nosotros somos testigos. $\downarrow$ Sin embargo, $\rightarrow$ hermanos, $\rightarrow$ sé que lo hicisteis por ignorancia, $\rightarrow$ y vuestras autoridades lo mismo $\downarrow$; pero Dios cumplió de esta manera lo que había predicho por los profetas, $\rightarrow_{-}$que su Mesías tenía que padecer. $\downarrow$

Frase entre dos comas [, ,], paréntesis [( )] y raya o guión largo [-]

Una frase entre dos comas, que indican brevísimas pausas, es como si estuviera dentro de un paréntesis [ ( )] o entre rayas o guiones largos [-]. En cada uno de ellos disminuimos ligeramente el tono o registro de la voz (como cuando, por ejemplo, hacemos una aclaración en tono más grave que indica ese paréntesis: «Me gustaría, si no tienes inconveniente, leerte esto»). Apliquémoslo a este pasaje del mismo libro, Hechos, 5: 17-18, 23: 7-8, y a Isaías 4: 14:

En aquellos días, $\rightarrow^{-}$el sumo sacerdote y los de su partido, $\rightarrow^{-}$-la secta de los saduceos-, $\rightarrow$ llenos de coraje, $\rightarrow$ mandaron prender a los apóstoles y meterlos en la cárcel común. $\downarrow$ Apenas dijo esto, $\rightarrow$ se produjo un altercado entre fariseos y saduceos y la asamblea quedó dividida. $\downarrow$ (Los saduceos sostienen que no hay resurrección ni ángeles ni espíritus, $\rightarrow$ mientras que los fariseos admiten todo esto). $\downarrow$

No temas, $\rightarrow$ gusanito de Jacob, $\rightarrow^{-}$ oruga de Israel, $\rightarrow^{-}$

yo mismo te auxilio $\rightarrow$

-oráculo del Señor-, $\downarrow$

tu Redentor es el Santo de Israel. $\rightarrow^{-}$

\section{Punto y seguido [.]}

Sin necesidad de tratar del punto final de párrafo, el punto o punto y seguido [.], fue inventado para hacer una pausa mayor que la indicada por la coma. Por ejemplo, en Éxodo 24: 4-7, en el que este signo separa cinco descripciones de muy significativas actividades:

Moisés puso por escrito todas las palabras del Señor. Se levantó temprano y edificó un altar en la falda del monte, y doce estelas, por las doce tribus de Israel. Y mandó a algunos jóvenes israelitas ofrecer al Señor holocaustos 
y vacas, como sacrificio de comunión. Tomó la mitad de la sangre y la puso en vasijas, y la otra mitad la derramó sobre el altar. Después tomó el documento de la alianza y se lo leyó en alta voz al pueblo...

\section{Sobre los finAles de LÍNEA}

Muchos lectores litúrgicos, aunque la frase termine en la línea siguiente, tienden a hacer una indebida pausa, como si hubiera una coma, al llegar al final de la línea, en lugar de unir ambas líneas en un necesario encabalgamiento. Esto, naturalmente, les obliga a recuperar la correcta curva de entonación, en los peores casos volviendo atrás y hasta repitiendo alguna palabra; o, peor aún, sin hacer nada porque ni han reconocido su error.

Esta falta es aún más corriente cuando quienes no están acostumbrados a leer en la iglesia se enfrentan con un texto fragmentado en forma de verso y hacen lo mismo, a pesar de que no hay puntuación alguna que lo justifique. El efecto es pésimo, pues cada vez que ocurre nos parece haber percibido algo ya completo, y entonces, tras descender el registro de su voz, el lector nos lee el resto como algo independiente que empieza.

Esto es lo que vemos ocurrir a veces, por ejemplo, en el Salmo 23: 5-6, que a veces oímos con pausas después de «mí», «acompañan» y «Señor», en lugar de completar la frase que continúa en la línea siguiente, indicado aquí usando de nuevo el símbolo [J]:

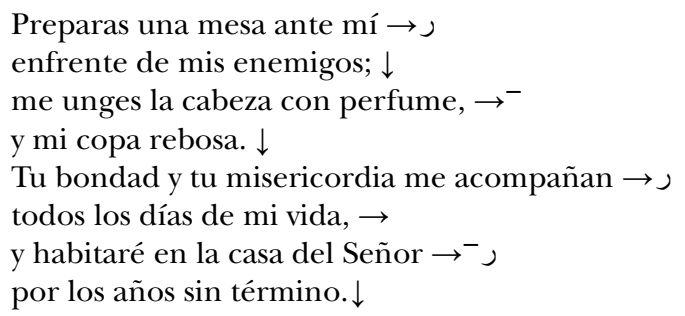

\section{LOS SILENCIOS COMO PORTADORES DE LAS PALABRAS INMEDIATAMENTE} PRECEDENTES

De entre lo mucho que puede decirse sobre el silencio en general (Poyatos 1998) y sobre los distintos tipos de silencio en la lectura litúrgica (Poyatos 2016b: 145-146), mencionemos al menos el valor comunicativo de los indicados por la puntuación, algunas de cuyas funciones hemos visto ya. Se trata concretamente de los silencios finales, con o sin contacto visual, y de su capacidad para actuar de manera no diferente a como actúan en nuestras interacciones sociales, es decir, como portadores de la actividad 
inmediatamente precedente; en el caso del lector, realzando las palabras que acaba de transmitir a la asamblea.

Si al leer la última frase de lo que completa una lectura, por ejemplo, « ¡Vosotros seréis mi pueblo, y yo seré vuestro Dios!», el lector hace un brevísimo silencio inmediatamente después (tal vez sin levantar aún la mirada para cerrar su lectura diciendo «Palabra de Dios»), esas palabras podrán prolongarse más intensamente en la mente de sus oyentes, transportadas y aumentadas por ese silencio y, claro, también por la quietud de cuerpo y cara. Por eso es un tipo de silencio que debería calcularse con vistas a una experiencia más intensa por parte de los oyentes, porque es estratégicamente comunicativo al amplificar y definir mucho mejor el significado de lo que se nos acaba de decir, repitiéndose en nuestra mente como un eco ${ }^{5}$.

Consideremos este tipo de silencio, indicado con $/ . . . . /$, en este texto de Isaías 61: 1:

Me ha enviado para dar la buena noticia

a los que sufren,

para vendar los corazones desgarrados,

para proclamar la amnistía a los cautivos, y a los prisioneros la libertad. /..../

Sin embargo, es muy común entre los lectores no reconocer que, tras declaraciones tan importantes como esta, los oyentes (como harían si lo leyeran por sí mismos) necesitan imprescindiblemente un tiempo para asimilar el alcance de esas palabras, mientras que, leyéndolas a un auditorio, cierran inmediatamente su lectura -que en sí misma consta de sonidos y silencios- diciendo «Palabra de Dios»; o, si se trata de un punto y seguido, simplemente continúan leyendo.

\section{Cara y gesto en el discurso del lector litúrgico}

Hemos visto cómo un lector, con las características y modificaciones paralingüísticas de su voz, puede hacer de la lectura de la Palabra algo vivo o algo mucho menos significativo, incluso insípido, sobre todo para el oyente menos formado y no familiarizado con esos textos. Pero en el marco litúrgico el gesto también debe acompañar a la voz, aunque casi imperceptiblemente.

No olvidemos que en esa triple actividad de nuestro hablar, lenguajeparalenguaje-kinésica, la cohesión y congruencia que normalmente existen

\footnotetext{
${ }^{5}$ Un estudio detallado de los silencios se encuentra en Poyatos (1994, vol. I, cap. 5), más extensamente en Poyatos (2002b, cap. 7 y 1998).
} 
entre las palabras, sus modificadores paralingüísticos (tono, ritmo, intensidad, etc.) y los gestos que las acompañan o alternan con ellas (consciente o inconscientemente), es algo que ocurre de una manera natural, aunque en algunas ocasiones -como en la lectura litúrgica-, uno conscientemente trate de controlar los dos cosistemas no verbales de ese discurso: paralenguaje y kinésica. Pero reconozcamos que se requiere un mínimo de expresión visible, y no solo la audible, para que la lectura invite a ser escuchada y sea capaz de ganarse la atención, por muy leve que sea la kinésica, sin que nunca pueda ser tan obvia que llame la atención hasta el extremo de hacer que nos distraigamos fijándonos en ella. Por eso, los lectores no deben nunca accionar con las manos. Sin embargo, en la predicación un obispo, sacerdote o diácono puede gesticular libremente, lo mismo que solo ellos pueden adoptar ciertos cambios de postura, cada cual con su estilo personal, en lo cual la oratoria ha cambiado a través de los años y de los siglos, tendiendo a un discurso de mayor naturalidad verbal-no verbal, es decir, en voz y gesto.

Pero tengamos siempre en cuenta que nuestra cara hablante es el canal primordial de nuestra comunicación visual, que cada uno hablamos a través de nuestros rasgos faciales personales permanentes, y que, en primer lugar, los demás perciben esos rasgos como dulces, abiertos, risueños, serios, severos, tristes, como de preocupación, etc. Esto quiere decir que cada lector y cada lectora debe ser muy consciente de la imagen que, sea o no verdadera, ofrece a los demás a través de esos rasgos faciales permanentes, porque a veces el atractivo que podamos encontrar, por ejemplo, en unos rasgos estáticos, pueden disminuir o aumentar al convertirse en rasgos dinámicos, mientras que otros a primera vista no atractivos en absoluto, pueden cobrar un encanto especial al hablar. Esto quiere decir, evidentemente, que el lector, maestro o profesor, que tenga algunos de esos rasgos de aspecto más negativo (por ejemplo, una persona que, por sus cejas, parece permanentemente ceñuda) tendrá que suavizarlos tratando de adoptar una expresión más abierta y positiva durante toda su lectura, independiente del tono que luego tenga que adoptar para las palabras que esté leyendo.

\section{El EJE INTERACTIVO EN EL DISCURSO PROCLAMATIVO: MIRADA HABLADA Y MIRADA SILENCIOSA}

Finalmente, como en cualquier estudio de la interacción personal, no debemos olvidar que en una conferencia o en una clase solemos censurar al hablante que parece estar desconectado de nosotros sus oyentes si está demasiado pendiente de sus notas o porque habla sin dirigir nunca su mirada a nadie. Pero el lector litúrgico, que no nos está transmitiendo nada suyo, porque es un mero instrumento intermediario para proclamarnos la 
Palabra, también debe tratar, como elemento esencial de su interacción con la asamblea, de establecer con su auditorio, en algunos brevísimos momentos, cierto contacto más allá de su voz misma, puesto que está compartiendo algo con alguien.

Esto requiere, si no una verdadera mirada, unilateral o mutua, sí lo que se llama eje interactivo, es decir, esa línea imaginaria entre hablante (durante su discurso) y oyente (cuya orientación también puede indicar interés o desinterés), por la cual los participantes confirman su interacción. Claro que esto en una iglesia no implica mirarse, puesto que la distancia entre ellos es mayor que la obligada en otras situaciones sociales. Las miradas del lector -no los predicadores- y sus oyentes no tienen que encontrarse precisamente, aunque los oyentes sí miran al lector, pero él no debe nunca mirar directamente a nadie, sino abarcar en algunos momentos a la asamblea en general, confirmando ese eje interactivo.

Puede lograrse este contacto visual, de modo natural e impersonal, de dos maneras: a) levantando la mirada hacia la asamblea mientras aún se dice, sin mirarla ya en el texto, la última palabra (o parte de ella) de alguna frase importante; $b$ ) mirando en silencio tras haber leído esa palabra -que tendrá más impacto al ser realzada por el silencio que sigue-, en ambos casos compartiendo visiblemente con los oyentes el mensaje clave del pasaje e invitando así a que escuchen, no simplemente oigan.

Por razones de espacio, hagamos (imaginando ya todos los rasgos paralingüísticos y kinésicos comentados hasta aquí) dos lecturas sucesivas de un mismo texto: las palabras tan conocidas y esperanzadoras (lo cual exige una lectura adecuada) transmitidas por el profeta en Ezequiel 37: 25-28. Primero, mirando a la asamblea mientras se dice aún cada una de esas palabras clave (o parte de ella), aquí subrayadas; después, para la mirada silenciosa, leyéndolas y haciendo a continuación una breve pausa, indicada con $<\cdot>$ :

Así dice el $\underline{\text { Señor }}<\cdot>$ :

«[...] Derramaré sobre vosotros un agua pura

que os purificará:

de todas vuestras inmundicias e idolatrías

os he de purificar.

Y os daré un corazón nuevo,

y os infundiré un espíritu nuevo $<\cdot>$;

arrancaré de vuestra carne el corazón de piedra,

y os daré un corazón de carne $<\cdot>$.

Os infundiré mi espíritu,

y haré que caminéis según mis preceptos,

y que guardéis y cumpláis mis mandatos $\langle\cdot\rangle$.

Y habitaréis en la tierra que di a vuestros padres.

Vosotros seréis mi pueblo,

y yo seré vuestro Dios $<\cdot>$. 


\section{Conclusión}

He intentado llamar la atención acerca de un tipo de discurso oral al que, con mayor o menos frecuencia, todos estamos expuestos. Para aquellos investigadores que se interesen por este tema mis observaciones pueden servir de acicate para ampliarlas en un estudio más detallado y profundo, muy conscientes de lo mucho que de no verbal encierran las lecturas litúrgicas si consideramos el discurso de los lectores en el marco total en que ocurren (Poyatos 2017). Esto supone también reconocer la presencia del entorno físico con todas sus características (ej., un grandioso templo, una pequeña capilla); y, a la vez, considerar: las circunstancias en que se llevan a cabo esas lecturas (ej., un funeral, una boda), los posibles elementos de distracción (a veces indebidamente añadidos a lo que es estrictamente la celebración), el comportamiento de los demás oyentes, nuestra relación proxémica con ellos, pues una o más de esas características pueden influir en la escucha y asimilación de esos textos leídos; y, finalmente, la dimensión cronémica de la lectura (y de la celebración misma), es decir, la relación entre la extensión de cada texto leído y el nivel de atención de cada oyente, como rasgo personal, pero también influido por las características del lector. 


\section{BIBLIOGRAFÍA}

Coeditores litúrgicos (2005): Ordenación General del Misal Romano.

CONGREGACIÓN PARA EL CULTO DIVINO Y LA DISCIPLINA DE LOS SACRAMENTOS (2004): El Sacramento de la Redención, Madrid: San Pablo.

PoYATOS, Fernando (1993): Paralanguage: A Linguistic and Interdisciplinary Interactive Speech and Sounds. Ámsterdam/Filadelfia: John Benjamins.

- (1994): La comunicación no verbal, 3 volúmenes, Madrid, Ediciones Istmo.

- (1998): «Los silencios en el discurso vivo y en la literatura: Para el estudio realista del lenguaje y su entorno», Oralia 1, 47-70.

- (2002a): Nonverbal Communication Across Disciplines, vol. I, Ámsterdam/Filadelfia: John Benjamins.

- (2002b): Nonverbal Communication Across Disciplines, vol. II, Ámsterdam/Filadelfia, John Benjamins.

- (2002c): Nonverbal Communication Across Disciplines, vol. III, Ámsterdam/Filadelfia, John Benjamins.

- (2003): «Los comportamientos no verbales como contexto y entorno del discurso oral», Oralia 6, 283-307.

- (2006): «Enfoque integral del habla andaluza y su entorno a través de los elementos verbales y no verbales de sus textos», Oralia 9, 277-302.

- (2008): Textual Translation and Live Translation: The Total Experience of Nonverbal Communication in Literature, Theater and Cinema, Ámsterdam/Filadelfia: John Benjamins.

- (2012): «Realidad y problemas del discurso verbal-no verbal en interpretación simultánea o consecutiva», Oralia 15, 279-303.

- (2016a): «El discurso en el contexto de la interacción personal y con el entorno en literatura», Oralia 19, 229-258.

- (2016b): Leer y Proclamar. Los ministros de la Palabra en la Celebración Eucarística, Madrid: De Buena Tinta.

- (2017): Comunicación no verbal y liturgia. Interacción personal y con el entorno en la celebración eucarística, Madrid: De Buena Tinta. 